\title{
Aging and pulmonary emphysema: Current issues
}

\author{
Patricia Morsch ${ }^{1}$, Kamila Mohammad Kamal Mansour ${ }^{2}$ and Andréa Lúcia Gonçalves da Silva ${ }^{3}$ \\ ${ }^{1}$ Faculdade de Educação e Meio Ambiente (FAEMA), Physical Therapy Course; Ariquemes, RO - Brazil \\ ${ }^{2}$ Physical therapy, University of Santa Cruz do Sul,- UNISC, Santa Cruz do Sul, RS, Brazil \\ ${ }^{3}$ Department of Health and Physical Education, University of Santa Cruz do Sul, (UNISC), Santa Cruz do Sul, RS, Brazil
}

\begin{abstract}
This review aims to describe emphysema and age-related factors that might influence on its development. In addition, available treatments for this lung disease will be presented. The older adult population has been increasing as well as life expectancy. This demographic change is accompanied by an epidemiological transition, represented by a high incidence of chronic diseases, such as pulmonary emphysema. Emphysema is a devastating illness characterized by the destruction of alveoli walls. Symptoms may vary depending on the severity of the disease, but most patients report having dyspnea and difficulty in exhaling air, due to reduced compliance of the lungs and airway obstruction. The fundamental cause of emphysema is still unknown. It is understood that there is a relationship between cell inflammatory responses to toxic substances, such as tobacco as well as an imbalance between proteases and antiproteases. However, it has been suggested that age can play a key role in the development of this disease, especially because of cell senescence. Even though treatments are available to reduce emphysema symptoms, and specific therapies aiming to regenerate lungs are being tested, more research about this disease is crucial to find its fundamental cause and clarify the role of age on its development. Avoiding environment factors such as tobacco smoking and exposure to pollutants can help to prevent this disease. The aim of this paper is to discuss emphysema, available treatments as well as research conducted about promising interventions for the future. Additionally, the paper aims to discuss how age can contribute to its development.
\end{abstract}

\section{Introduction}

The study of aging has increased due to the worldwide phenomenon of population aging as well as to the increase in life expectancy. These facts impact health care in all aspects and because of this, require special knowledge [1]. Balcombe and Sinclair [2] suggest that the increased life expectancy can be seen, for some people, as a successful achievement; however, others can argue that it is not, since many older adults might face these extra years with a chronic condition.

Age is a risk factor to the development of different chronic diseases, given the age-related changes in tissues and systems. However, it is known from current studies with animals, especially wild ones, that environment play an important role in aging and life expectancy [2].

Aging and, more precisely, senescence causes degenerative changes in cells, tissues and systems leading to dysfunction and death. Antioxidant capacity is affected by age-related changes in hydrophilic radical scavengers (ascorbate, urate and glutathione), lipophilic radical scavengers (tocopherols, carotenoids), metal chelators and antioxidant enzymes, such as superoxide dismutase, catalase and glutathione peroxidase: Cell antioxidant capacity and oxidative stress are critical factors in the aging process. Reactive oxygen species (ROS) and other free radicals may damage cell membranes, particularly because of the oxidation of lipids, proteins and DNA, which may lead to cell dysfunctions and aging, carcinogenesis, neurodegenerative and cardiovascular diseases. DNA damage and DNA repair seem to be closely associated with aging [3].

Some diseases, such as emphysema, are more common in older adults but not exclusive for them ${ }^{2}$. Emphysema is characterized by a destructive process of the lung parenchyma resulting in permanent enlargement of air spaces distal to the terminal bronchioles. It is caused by cigarette smoking and associated with inhalation of smoke and dust [4]. This condition is also one of the main types of Chronic Obstructive Pulmonary Disease (COPD) as classified by the Global Initiative of Chronic Obstructive Lung Disease [5] (GOLD). COPD is considered a severe health problem since it is one of the most important causes of morbidity and mortality in the United States and in developed countries. In the United States, COPD affects 6,5\% of the adult population; it is the third leading cause of death and the 12th leading cause of morbidity. Additionally, by 2030 it is expected to be the 7 th cause of death worldwide, representing over 4.5 million deaths annually due to COPD and related conditions [5-7]. The total economic costs of COPD in the United States were estimated at \$32.1 billion dollars annually with a rise in medical costs expected to reach $\$ 49$ billion by 2020 [8]. The most frequently described comorbidities include skeletal muscle waste, cachexia, pulmonary hypertension, lung cancer, congestive heart failure, ischemic heart disease, hyperlipidemia, normocytic anemia, diabetes, metabolic syndrome, osteoporosis, obstructive sleep apnea, depression, and arthritis $[9,10]$.

COPD generally manifests at older ages, but there is evidence that events early in life, including exposure to noxious stimuli in the uterus may have long-term effects on lung health contributing to impaired lung function when older [11]. This disease among older adults is associated with a poor prognosis, usual hospitalization and increased

Correspondence to: Patricia Morsch, Faculdade de Educação e Meio Ambiente (FAEMA), Physical Therapy Course; Ariquemes, RO - Brazil, E-mail: patriciamorsch@hotmail.com

Key words: Emphysema, aging, interventions, cell aging, chronic obstructive pulmonary disease

Received: November 03, 2017; Accepted: December 04, 2017; Published: December 08, 2017 
mortality rate. However, age-related mechanisms causing emphysema are not clear [12].

The present review aims to describe emphysema and age-related factors that might influence on its development. In addition, available treatments for this lung disease will be presented.

\section{Pulmonary emphysema}

Emphysema is a devastating disease, in which the alveoli walls are destroyed and enlarged, reducing the surface area for gas exchange and limiting lungs' elastic recoil [13-15]. An emphysematous lung presents airways inflammation, increased production of mucus and mild to severe pulmonary hypertension, causing air obstruction [14,16,17]. Patients' main complaints are usually breathlessness and difficulty in exhaling air, possibly caused by reduced elasticity and compliance of the lungs ${ }^{13}$. However, symptoms may vary depending on how advanced is the disease: individuals with mild emphysema commonly do not present symptoms at quiet breathing. In case of advanced disease, patients present barrel-shaped chest, weight loss, productive and chronic cough with or without sputum production, increased shortness of breath and constant use of breathing accessory muscles, poor exercise tolerance, and wheezing to respiratory failure or cor pulmonale $[14,18,19]$.

The clearest signs of emphysema are seen in chest radiography which shows signs of hyperlucent lungs, reduced diffusion capacity and hyperinflation of the lungs $[13,18]$. However, Lee et al. [18] claim that $\mathrm{x}$-ray chest is not very helpful to identify mild emphysema and because of this it is more common for emphysema to be diagnosed in an advanced stage. Computed tomography (CT) of the thorax can be also a diagnosis tool to detect the disease at an early stage. Incidental CT findings of emphysema and airway thickening, seen on routine diagnostic CT scans, performed for nonpulmonary clinical symptoms, may help find probable patients with COPD [20]. Guest [13] also describes the difficulty in identifying emphysema, since it is usually correlated with other diseases. For example, asthma and chronic bronchitis also lead to airway obstruction. This confusion of diseases and symptoms may delay emphysema diagnoses and compromise treatment [13].

An effective way to diagnose this disease might be performing a lung function test. The most efficient measure is the forced expiratory volume in one second $\left(\mathrm{FEV}_{1}\right)$ [18]. This test can diagnose as well as demonstrate how severe the disease is and suggest patients' prognosis; it is expected from patients with COPD a progressive decline in $\mathrm{FEV}_{1}$. However, Guest [13] claim that the test cannot provide a clear emphysema diagnosis because the same results are expected for other airway obstruction diseases. Consequently, emphysema might be clinically underdiagnosed, especially in older adults, who have usually association of chronic conditions, overlapping symptoms and difficulty in understanding respiratory function evaluation test [21]. Löndahl et al. [22] suggest a new tool to assess abnormalities in the peripheral regions of the lungs, the method consists on airspace dimension assessment by nanoparticles, the authors considered this method less time consuming, cheaper, simpler to use, and easier to interpret than imaging exams.

The first recommendation of the American College of Physicians (ACP), American College of Chest Physicians (ACCP), American Thoracic Society (ATS) and European Respiratory Society (ERS) guidelines, is to conduct spirometry to diagnose airflow obstruction in patients with respiratory symptoms, particularly dyspnea. Spirometry should not be used to screen airflow obstruction in individuals without respiratory symptoms [19]. This update indicates that the best variable for identifying adults with airflow obstruction is a smoking history greater than 40 pack-year. A combination of findings is more helpful for diagnosing airflow obstruction than is any individual sign, symptom, or piece of historical information. The combination of all 3 of the following items-patient-reported smoking history greater than 55 pack-year, wheezing on auscultation; and patient self-reported wheezing-almost confirms the presence of airflow obstruction. In addition, the absence of all 3 items practically rules out airflow obstruction [19].

Different causes, and its interactions, are considered in the development of emphysema. Among them, better understood are inflammatory reactions of cells, mainly related to toxic exposure, such as tobacco. Others, for example apoptosis, are still under investigation [23]. Karrasch et al. [24] suggest that cells senescence can play an important role in the development of emphysema as well. Rodrigues et al. [25] have found in a model of emphysema induced by porcine pancreatic elastase instillation and exposure to cigarette smoke a significant degree of parenchymal destruction in a short period. Their findings strengthen the role of protease-antiprotease/oxidantantioxidant imbalance in the pathogenesis of emphysema and that a murine model could be useful to evaluate the structural changes that occur during the processes of destruction and remodeling of the pulmonary parenchyma in emphysema.

\section{Age-related mechanisms as probable causes for emphysema}

There is wide evidence of shared features between pulmonary emphysema and aging lung ${ }^{26}$. With aging the respiratory system undergoes many changes in its structure and function resulting from interaction between individuals and environmental stresses. However, how the aging process contributes to the development of emphysema must be better understood $[12,17]$. The most important age-related change associated with emphysema might be the reduction in alveolar structures [24].

The cellular equivalent of aging is senescence, which is characterized by a nonproliferative state in which cells are metabolically active and apoptosis-resistant. Several molecular and cellular mechanisms are associated with cellular senescence including accumulation of DNA damage, impairment of DNA repair epigenetic modifications in nuclear DNA, protein damage from oxidative stress, and telomere attrition $[3,26]$. COPD following smoking is a disease-related senescence it causes DNA damage from compounds present in cigarettes that leads to telomere shortening, due to a greater need for repair on airway epithelium, after being injured by toxic substances. DNA damage and telomere shortening happen during healthy aging, but in smoking, the intensity of the stress is faster. Most of impairments in this disease occurs in the lung, thus smoking-induced senescent cells are probably located there [27].

Telomere shortening, related to cell senescence, might help in the development of emphysema in older adults [12]. According to Karrasch et al. [24] telomere shortening may reduce tissue repair properties, limiting the maintenance of organs and systems. In addition, reduced length of telomere is related to dysfunctions in the immune system, which can lead to impairments in one organ. Telomere lengths are not entirely genetically inherited, accelerated telomeric loss can happen because of different environmental factors such as genotoxicity, air pollution and tobacco exposure [28]. Research has shown that telomeres are shorter in individuals with emphysema compared to non-smokers 
with the same age ${ }^{12}$. Albrecht et al. [29] in a meta-analysis of seven studies with 12,595 individuals, found significant associations among telomere length from peripheral leukocytes and spirometric indices measured by $\mathrm{FEV}_{1}$, FVC and Tiffeneau-pinelli index.

It is important to consider that the lungs are constantly exposed to pollutants and sometimes to inflammatory processes and oxidants, which might alter lung properties requiring constant repair. Reactive oxygen species (ROS) and other free radicals may damage cell membranes, particularly because of the oxidation of lipids, proteins and DNA. DNA damage and DNA repair seem to be closely associated with aging. Moreover, unlike proteins and lipids, new molecules of DNA cannot be synthesized to replace damaged DNA [30]. As a long-term result, with aging, this continuous remodeling can no longer be done, favoring the occurrence of diseases such as emphysema ${ }^{30}$. Apart from telomere shortening, the reduced ability of the alveolar tissue to repair can be attributed to lipofuscin, which was found in emphysematous lungs [12].

Also, the production of oxygen-derived free radicals is increased, inducing aging of the lungs and activation of multiple genes responsible to encode pro-inflammatory molecules [17]. Research conducted by MacNee [31] suggested that free radicals play a significant role in the development of emphysema, and COPD patients' have a decreased antioxidant capacity [17].

Telomere dysfunction is influenced by age, but also by external factors, such as psychological stress and oxidative stress, the last caused by smoking [24]. Cigarette smoking and aging are related to oxidative stress, which increases cell apoptosis. This phenomenon was found to be associated with increased levels of destruction of alveoli walls in individuals with emphysema $[17,23]$.

Smoking is also related to chronic inflammation of the airways, which is crucial to the development of emphysema. Most of the diseases affecting older adults are related to some kind of inflammation and persistent increase in the proinflammatory cytokines IL- 6 and IL8 , shown to be induced by cigarette smoke and present in increased levels in lungs of individuals with COPD, are also triggered by aging [26]. Senescence/aging can lead to decrease in stem/progenitor cells and the reduced activity of the immune system in older adults helps to the development of inflammation processes $[17,26]$. In the case of emphysema, there is a higher circulation of inflammatory cells or specific concentration of pro-inflammatory cytokines.

Another possible cause for emphysema is an imbalance between proteases and antiproteases. This situation can promote cell dysfunctions regarding their maintenance ability. In addition, proteases can destroy lung intercellular matrix, leading to apoptosis [30]. Research conducted by Tsuji et al. [12] found that when alveolar cells show signs of senescence, apoptosis can no longer be compensated for proliferation of new cells, leading to destruction of the alveolar tissue. Lung tissue destruction occurs due to the mutual interaction among alveolar cell apoptosis, oxidative stress, and protease/antiprotease imbalance. Inflammation can be triggered and amplified by alveolar injury, including either enhanced alveolar cell apoptosis or defective apoptotic cell clearance $[26,32,33]$.

Recent data from animal models of COPD as well as from studies in human beings suggest that another mechanism might be involved in the pathogenesis of COPD: disruption of the balance between apoptosis and replenishment of structural cells in the lung might contribute to the destruction of lung tissue in response to cigarette smoke, leading to emphysema. More studies are needed to identify the most important apoptotic pathway and the caspases involved in the development of COPD. Moreover, research is needed to clarify if apoptosis can be used as a therapeutic target to prevent further deterioration of the disease, which occurs even after the patients have quit smoking. Finally, as disturbance of the balance between apoptosis and regeneration of structural lung cells seems important in the destruction of healthy lung tissue, it would be interesting to evaluate the potential use of stem cell therapy for emphysema $[34,35]$.

Genetically modified mice have helped to identify factors underlying emphysema [24]. Sato et al. [15] conducted a research on the development of emphysema in klotho mouse, a genetically modified rodent with accelerated aging [30], and found that klotho mouse has similar development of emphysema that human beings: when aging, after 7 weeks of life, they present destruction and enlargement of alveoli walls. Hence, age might have great influence in the development of emphysema [30].

Onodera et al. [36] investigated the role of growth differentiation factor 11 (GDF11), in vitro and in vivo models, in cellular senescence. This protein is an anti-ageing factor that is reduced at the plasma and lungs of COPD patients and is significantly correlated with disease severity. GDF11 showed anti-senescent effects in lung cells on both models. These findings suggest that GDF11 may have a part in the senescence observed in these patients, and that may be a future perspective in elucidating the mechanisms of cellular senescence in COPD.

Causes of emphysema and how age contributes to its development still need to be clarified. The use of rodents to investigate the morphology of pulmonary emphysema might be a possible model of research [15], which might help in the development of more effective treatments.

\section{Interventions for emphysema: effectiveness and safety}

As a consequence of the lack of knowledge in the fundamental cause of pulmonary emphysema, treatments are available to reduce symptoms, but none of them can stop the disease progression and decrease mortality rates yet. Research has been carried out and there are some innovations in medicine that might be efficient against this devastating disease [17]. Treatments for emphysema, especially when it is smoke related, comprehend the use of bronchodilators, supplemental oxygen for hypoxemia, non-invasive ventilation, exercise for pulmonary rehabilitation, prevention for secondary diseases and, when indicated, lung transplantation especially in patients younger than 60 years old $[18,37,38]$. For stable COPD patients with respiratory symptoms and $\mathrm{FEV}_{1-} 60 \%$ predicted, the ACP, ACCP, ATS, and ERS recommend treatment with inhaled bronchodilators and the clinicians should base the choice of specific monotherapy on patient preference, cost, and adverse effect profile. Also, the recommendation that clinicians may administer combined inhaled therapies (long-acting inhaled anticholinergics, long-acting inhaled-agonists or inhaled corticosteroids) for symptomatic patients with stable COPD and $\mathrm{FEV}_{1-} 60 \%$ of predicted [19]. Pharmacological treatments may reduce symptoms, risk and severity of exacerbations, improve overall health status and exercise capacity [5].

Long-term administration of oxygen increase survival in patients with severe resting hypoxemia, but it does not lengthen time to death or first hospitalization or provide sustained benefit for any of the measured outcomes in patients with stable COPD [39]. The 
recommendation of the ACP, ACCP, ATS, and ERS for clinicians, is that they should prescribe continuous oxygen therapy in patients with COPD who have severe resting hypoxemia $\left(\mathrm{PaO}_{2} \_55 \mathrm{~mm} \mathrm{Hg}\right.$ or $\mathrm{SpO}_{2} \_88 \%$ ) [19]. The mechanism in which oxygen works is based on reducing dyspnea and the respiratory rate while exercise, promoting a more efficient exhalation [16].

Pulmonary rehabilitation is a useful intervention to control symptoms and improve functional capacity in individuals with emphysema. Ries et al. [40] mentioned a research conducted by the National Emphysema Treatment Trial (NETT) which suggested that individuals with emphysema have significant improvements in exercise capacity, breathlessness, and health-related quality of life after pulmonary rehabilitation. Pulmonary rehabilitation is also important in preparing patients for other treatments, such as surgery, because of the improvements in individual's physical and emotional status [40]. The ACP, ACCP, ATS, and ERS recommend that clinicians should prescribe pulmonary rehabilitation for symptomatic patients with an $\mathrm{FEV}_{1} \_50 \%$ of predicted [19].

Lung Volume Reduction (LVR) is a surgery in which lung volume is reduced by various wedge resections. This intervention improves ventilation-perfusion mismatch and cardiopulmonary hemodynamics, improving ventilatory mechanics by decreasing hyperinflation, elastic recoil and airway tethering, increasing respiratory muscle efficiency and survival rates, consequently promoting quality of life and improved exercise capacity. Based on NETT's data, LVR is indicated for patients with severe symptoms, $\mathrm{FEV}_{1}$ of less than $45 \%$ of predicted, diffusing capacity of the lung for carbon monoxide of more than $20 \%$ of predicted [41,42]. Stolk et al. [43] tested bone marrow mesenchymal stem cells (BM-MSCs) administration safety and feasibility after LVR. The study showed positive results in which BM-MSC infusions might stimulate microvascular endothelial cells in the most affected parts of the lung, the treatment also resulted in increased $\mathrm{FEV}_{1}$, body weight gain, higher levels of interleukin-10 and tumor necrosis factor- $\alpha$ stimulated gene/protein 6 .

Although treatments with BM-MSCs are showing optimistic results in different lung disorders, including emphysema, showing a decrease in tissue destruction in elastase-induced emphysema, through secretion of paracrine factors such as epidermal growth factor [44], the use of MSCs are not fully understood. This new treatment modality for COPD patients is currently tested on clinical trials, varying in distinct stages of COPD, route of injection, type and dosage of cells, and outcomes [45]. MSCs show profound suppressive effects on immune cells and pathways, recent studies have indicated that MSCs suppress lung injury and inflammation in mouse models of inflammatory and immune mediated lung diseases [46].

Stermann et al. [37] conducted a research implanting a bronchial valve in patients with severe emphysema. Their aim was to reduce atelectasis and lung volume. This method can be a promising treatment for the future, because it showed to be safe and promoted a better quality of life for patients. Bronchoscopic LVR with endobronchial valves (EV) treatment have been shown to improve pulmonary function, physical activity levels, exercise capacity and quality of life in patients with severe emphysema characterized by an absence of collateral ventilation $[47,48]$. In a meta-analysis conducted by Wang et al., [7] bronchoscopic lung volume reduction therapy in patients with severe emphysema improved pulmonary function, exercise capacity, and quality of life compared with conventional therapy.

In case of emphysema being a consequence of oxidative stress and aging, antioxidants may be effective as an anti-COPD drug.
Antioxidants available are not strong enough, but more potent drugs have been developed to be a possible intervention to decrease rapid aging of the lung [17].

Treatments are available to restore balance between protease and antiprotease. Even though there is no randomized research done confirming its effectiveness, observational studies suggest that the therapy is effective slowing down the decrease in lung function for individuals with moderate emphysema. Additionally, individuals who tried the treatment had higher survival rates [18].

Golpon and Volkel [16] describe a novel approach to treat emphysema: the use of vascular growth factors. The experiments conducted with mice suggest that exogenous growth factors promote cell proliferation in the alveolar wall increasing lung regeneration and angiogenese. In humans, fibroblast growth factor through Fgf10 expression marks a subset of lipofibroblasts, an important cell type in the stage of lung development that provide type 2 alveolar epithelial cells with triglycerides which are needed for production of surfactant. This leads to recapitulation of alveologenesis, that could be used in treatment of alveolar destruction, a hallmark in emphysema. However, caution is needed when considering this treatment: it is still unknown if the results will be the same in human beings $[16,49]$.

On their review, Oh et al. [50] show positive perspectives on lung regeneration therapy, but they point out that the use of this therapy remains unclear and must be tested in better-designed clinical trials. The authors call attention to stem cells' tumorigenicity properties and the use of retinoids, because they can lead to cancer or vascular diseases.

Treatment options for emphysema are summarized in a review conducted by Shah et al., [51]. Patients with severe emphysema and hyperinflation must be considered for LVR and lung transplantation. Those with paraseptal or heterogeneous emphysema also should be considered for LVR. For patients with heterogeneous upper lobepredominant disease with intact lobar fissures or absent collateral ventilation $\mathrm{EV}$ is recommended. All patients, regardless severity of the disease, should be introduced to rehabilitation programs. The authors emphasize that treatment decisions should be made by a multidisciplinary group with the patients.

\section{Conclusion}

There is a strong relationship between aging and emphysema. Cell senescence caused by aging and environmental factors play a significant role in the development of this lung disease; however, the morphological mechanism for the occurrence of emphysema is still not fully understood. Animal research has been efficient giving a better understanding of emphysema. However, an increase in research is crucial to find the fundamental cause of this lung disease and clarify the role of age on its development. This knowledge and the improvement in health technology may help the implementation of more efficient treatments for the future. The study of stem cells is a promising treatment for emphysema, because it can be an effective method to regenerate the lungs and the alveoli tissue, but it still has some barriers to overcome.

People can modify environment factors related to emphysema and somehow be able to prevent this devastating disease. A current trend is the implementation of public awareness of emphysema, prevention of tobacco and exposure to other pollutants. Encouraging people to prevent this disease is needed since emphysema have a significant impact in individuals and society. 


\section{Authorship and contributions}

Patricia Morsch: designed the review, contributed to develop the study, reviewed the literature, and approved the final version.

Kamila Mohammad Kamal Mansour: contributed to develop the study, reviewed the literature, and formatted into the final version.

Andréa Lúcia Gonçalves da Silva: contributed to develop the study, reviewed the literature, and reviewed the final version

\section{Conflict of interest}

The authors declare no conflict of interest

\section{References}

1. Janssens JP (2005) Aging of the respiratory system: impact on pulmonary function tests and adaptation to exertion. Clin Chest Med 26: 469-4s84.

2. Balcombe NR, Sinclair A (2001) Ageing: definitions, mechanisms and the magnitude of the problem. Best Practice and Research Clinical Gastroenterology 15: 835-849.

3. Mergener M, Martins MR, Antunes MV, da Silva CC, Lazzaretti C, et al. (2009) Oxidative stress and DNA damage in older adults that do exercises regularly. Clin Biochem 42: 1648-1653. [Crossref]

4. Kemp SV, Polkey MI, Shah PL (2009) The epidemiology, etiology, clinical features, and natural history of emphysema. Thorac Surg Clin: 149-58.

5. GOLD - Global Initiative for Chronic Obstructive Lung Disease (2017) Global Strategy for the diagnosis, management, and prevention of chronic obstructive pulmonary disease.

6. World Health Organization. Projections of mortality and causes of death, 2015 and 2030.

7. Wang Y, Lai TW, Xu F, Zhou JS, Li ZY, et al. (2017) Efficacy and safety of bronchoscopic lung volume reduction therapy in patients with severe emphysema. a meta-analysis of randomized controlled trials. Oncotarget, Advance Publications.

8. Ford ES, Murphy LB, Khavjou O, Giles WH, Holt JB, et al. (2015) Total and StateSpecific Medical and Absenteeism Costs of COPD Among Adults Aged $=18$ Years in The United States For 2010 And Projections Through 2020. Chest 147: 31-45.

9. Barnes N, Calverley PM, Kaplan A, Rabe KF (2013) Chronic obstrucive pulmonary disease and exacerbations: patient insights from the global Hidden Depths of COPD survey. BMC Pulm Med. 13: 1-11.

10. Foo J, Landis SH, Maskell J, Oh YM, Molen TVD, et al. (2016) Continuing to Confront COPD International Patient Survey: Economic Impact of COPD in 12 Countries. PLoS ONE 11: e0152618.

11. Martinez FD (2016) Early-Life Origins of Chronic Obstructive Pulmonary Disease. $N$ Engl J Med 375: 871-878. [Crossref]

12. Tsuji T, Aoshiba K, Nagai A (2007) Alveolar senescence in patients with pulmonary emphysema. Am J Respir Crit Care Med 174: 886-893.

13. Guest J (1998) Assessing the cost of illness of emphysema. Disease Management and Health outcome 3: 81-88.

14. Kim V, Steiner RM (2007) Interventional treatment options for advanced emphysema: imaging manifestations. $J$ Thorac Imaging 24: 195-205.

15. Sato A, Hirai T, Imura A, Kita N, Iwano A, Muro S, et al. (2007) Morphological mechanism of the development of pulmonary emphysema in klotho mice. Proc Natl Acad Sci USA 104: 2361-2365.

16. Golpon HA, Voelkel NF (2006) The vasculature as a target in the treatment of pulmonary emphysema. Curr Drug Targets 7: 737-741. [Crossref]

17. Ito K, Barnes PJ (2009) COPD as a disease of accelerated lung aging. Chest 135: 173180. [Crossref]

18. Lee P, Gildea T, Stoller J (2002) Emphysema in nonsmokers: alpha 1-antitrypsin deficiency and other causes. Cleve Clin J Med 69: 928-929, 933, 936.

19. Qaseem A, Wilt TJ, Weinberger SE, Hanania NA, Criner G, et al. (2011) Diagnosis and management of stable chronic obstructive pulmonary disease: a clinical practice guideline update from the American College of Physicians, American College of Chest Physicians, American Thoracic Society, and European Respiratory Society. Ann Intern Med 155: 179-91.

20. Jairam PM, Van Der Graaf Y, Lammers JW, Mali WP, de Jong PA, PROVIDI Study group (2015) Incidental findings on chest $\mathrm{CT}$ imaging are associated with increased COPD exacerbations and mortality. Thorax 70: 725-731.
21. Koblizek V, Novotna B, Zbozinkova Z, Hejduk K (2016) Diagnosing COPD: advances in training and practice - a systematic review. Adv Med Educ Pract 7: 219-231. [Crossref]

22. Löndahl J, Jakobsson JK, Broday DM, Aaltonen HL, Wollmer P (2016) Do nanoparticles provide a new opportunity for diagnosis of distal airspace disease? Int J Nanomedicine 12: 41-51. [Crossref]

23. Wright JL, Churg A (2007) Current concepts in mechanisms of emphysema. Toxicol Pathol 35: 111-115. [Crossref]

24. Karrasch S, Holz O, Jorres R (2008) Aging and induced senescence as factors in the pathogenesis of lung emphysema. Respir Med 102: 1215-1230.

25. Rodrigues R, Olivo CR, Lourenço JD, Riane A, de Brito Cervilha DA, et al. (2017) A murine model of elastase- and cigarette smoke-induced emphysema. J Bras Pneumol 43: $95-100$

26. MacNee W, Tuder RM (2009) New paradigms in the pathogenesis of chronic obstructive pulmonary disease I. Proc Am Thorac Soc 6: 527-531. [Crossref]

27. Childs BG, Durik M, Baker DJ, van Deursen JM (2015) Cellular senescence in aging and age-related disease: from mechanisms to therapy. Nature medicine. 21: 1424-1435.

28. Opresko PL, Shay JW (2017) Telomere-associated aging disorders. Ageing Res Rev 33: 52-66. [Crossref]

29. Albrecht E, Sillanpää E, Karrasch S, Alves AC, Codd V, et al. (2014) Telomere length in circulating leukocytes is associated with lung function and disease. Eur Respir $J 43$ : 983-992. [Crossref]

30. Tuder RM, McGrath S, Neptune E (2003) The pathobiological mechanisms of emphysema models: what do they have in common? Pulm Pharmacol Ther 16: 67-78. [Crossref]

31. MacNee W (2001) Oxidative stress and lung inflammation in airways disease. Eur $J$ Pharmacol 429(1-3): 195-207.

32. Bargagli E, Olivieri C, Bennett D, Prasse A, Muller-Quernheim J, et al. (2009) Oxidative stress in the pathogenesis of diffuse lung diseases: a review. Respir Med 103 1245-1256. [Crossref]

33. Gourab Choudhury, William MacNee (2016) Role of Inflammation and Oxidative Stress in the Pathology of Ageing in COPD: Potential Therapeutic Interventions. COPD 14: 122-135.

34. Demedts IK, Demoor T, Bracke KR, Joos GF, Brusselle GG (2006) Role of apoptosis in the pathogenesis of COPD and pulmonary emphysema. Respir Res 7: 53. [Crossref]

35. Bodas M, Vij N (2017) Augmenting autophagy for prognosis based intervention of COPD-pathophysiology. Respir Res 18: 83. [Crossref]

36. Onodera K, Sugiura H, Yamada M, Koarai A, Fujino N, et al. (2017) Decrease in an anti-ageing factor, growth differentiation factor 11 , in chronic obstructive pulmonary disease. 72: 893-904

37. Stermann DH, Mehta AC, Wood DE, Mathur PN, McKenna Jr. RJ, et al. (2010) A multicenter pilot study of bronchial valve for the treatment of severe emphysema. Respiration 79: 222-233.

38. Inci I, Schuurmans M, Ehrsam J, Schneiter D, Hillinger S, et al. (2015) Lung transplantation for emphysema: impact of age on short- and long-term survival. Eur $J$ Cardiothorac Surg 48: 906-909. [Crossref]

39. Long-term Oxygen Treatment Trial Research Group (2016) A randomized trial of longterm oxygen for COPD with moderate desaturation. NEJM 375: 1617.

40. Ries AL, Make BJ, Lee SM, Krasna MJ, Bartels M, et al. (2005) The effects of pulmonary rehabilitation in the National Emphysema Treatment Trial. Chest 128: 3799-3809.

41. Fishman A, Martinez F, Naunheim K (2003) National Emphysema Treatment Trial Research Group. A randomized trial comparing lung-volume-reduction surgery with medical therapy for severe emphysema. N Engl J Med 348: 2059-2073.

42. Mirza S, Benzo R (2017) Chronic Obstructive Pulmonary Disease Phenotypes: Implications for Care. Mayo Clin Proc. 92: 1104-1112.

43. Stolk J, Broekman W, Mauad T, Zwaginga JJ, Roelofs H, et al. (2016) A phase I study for intravenous autologous mesenchymal stromal cell administration to patients with severe emphysema. 109: 331-336.

44. Katsha AM, Ohkouchi S, Xin H, Kanehira M, Sun R, Nukiwa T, et al. (2011) Paracrine factors of multipotent stromal cells ameliorate lung injury in an elastase induced emphysema model. Mol Ther. 19: 196-203. 
45. Cheng S-L, Lin C-H, Yao C-L (2017) Mesenchymal Stem Cell Administration in Patients with Chronic Obstructive Pulmonary Disease: State of the Science. Stem Cells Int: 8916570 .

46. Weiss DJ, Bertoncello I, Borok Z, Kim C, Panoskaltsis-Mortari A, et al. (2011) Stem cells and cell therapies in lung biology and lung diseases. Proc Am Thorac Soc 8: 223272. [Crossref]

47. Klooster K, Hacken NH, Hartman JE, Kerstjens HA, van Rikxoort EM, et al. (2015) Endobronchial Valves for Emphysema without Interlobar Collateral Ventilation. $N$ Engl J Med: 2325-2335.
48. Hartman JE, Klooster K, Slebos, D-J, Hacken NHT (2016) Improvement of physical activity after endobronchial valve treatment in emphysema patients. Respir Med 117: 116-121.

49. El Agha E, Seeger W, Bellusci S (2017) Therapeutic and Pathological Roles of Fibroblast Growth Factors in Pulmonary Diseases. Dev Dyn 246: 235-244.

50. Oh DK, Kim YS, Oh YM (2017) Lung Regeneration Therapy for Chronic Obstructive Pulmonary Disease. Tuberc Respir Dis (Seoul) 80: 1-10. [Crossref]

51. Shah PL, Herth FJ, van Geffen WH, Deslee G, Slebos DJ (2017) Lung volume reduction for emphysema. Lancet Respir Med 5: 147-156. [Crossref]

Copyright: $\odot 2017$ Morsch P. This is an open-access article distributed under the terms of the Creative Commons Attribution License, which permits unrestricted use, distribution, and reproduction in any medium, provided the original author and source are credited. 